\title{
Separation and Structure of Methyl Methacrylate Telomers Synthesized in the Presence of Bromotrichloromethane
}

\author{
Takao Kimura, Tetsuji KodaIRA, ${ }^{*}$ and Motome Hamashima \\ Department of Environmental Chemistry, Faculty of Engineering, \\ Utsunomiya University, 2753, Ishii-cho, Utsunomiya 321, Japan
}

(Received October 14, 1982)

\begin{abstract}
The radical telomerization of methyl methacrylate (MMA) was carried out at $50-90^{\circ} \mathrm{C}$ using bromotrichloromethane (BTCM) as a chain transfer agent, and the $n$ [MMA]: [BTCM] adducts, that is, the $n$-mers, where, $n=1-3$, were separated by silica-gel column chromatography. The tacticities of two dimers and three trimers were estimated by ${ }^{1} \mathrm{H}$ NMR spectroscopy. Syndiotactic diastereoisomers were formed preferentially, and no isotactic trimer was found. The most stable conformations of the syndiotactic- and isotactic-dimers were presumed from the results of induced reactions.
\end{abstract}

KEY WORDS Radical Telomerization / Methyl Methacrylate / Bromotrichloromethane / Telomers / Silica-Gel Column Chromatography / Diastereoisomer / ${ }^{1} \mathrm{H}$ NMR / Tacticity / Conformation /

The addition reactions of bromotrichloromethane (BTCM) with various olefins have been studied by several workers, ${ }^{1,2}$ and BTCM has been pointed out to be an excellent radical addition reagent.

Furthermore, BTCM is known as a strong telogen for the radical telomerization of vinyl monomers. Kharasch et al. ${ }^{2-6}$ investigated kinetically the photoinitiated reaction between styrene and BTCM, and proposed a reaction mechanism. Barson et al. ${ }^{7-10}$ carried out the telomerizations of styrene and methyl methacrylate (MMA) in similar systems, and determined transfer constants for the telomeric radical intermediates using gel-permeation chromatography (GPC).

However, the separation and structural analysis of telomers synthesized using BTCM as a telogen have rarely been reported except some $1: 1$ adducts. ${ }^{2}$ Since the corresponding telomers have labile substituent groups on both ends, they can be considered as the starting materials for subsequent reactions. These studies on lower polymers afford valuable data as model compounds of higher polymers.
Recently, Fujishige ${ }^{11,12}$ studied the ${ }^{1} \mathrm{H}$ NMR spectra of MMA oligomers prepared through anionic oligomerization initiated with sodium methoxide. Bledzki et al. ${ }^{13-15}$ isolated MMA oligomers obtained by radical oligomerization using 1,1,2,2-tetraphenyl-1,2-diphenoxyethane as the initiator, and identified two kinds of dimers and three kinds of trimers by ${ }^{1} \mathrm{H}$ NMR spectroscopy.

This article deals with the separation and structure of MMA telomers up to trimers synthesized in the presence of BTCM as the telogen. The tacticity and the conformation of the diastereoisomers are discussed in reference to the data obtained through ${ }^{1} \mathrm{H}$ NMR spectroscopy and induced reactions.

\section{EXPERIMENTAL}

\section{Measurements}

GPC analysis of the telomers was carried out with a Hitachi 635 chromatograph (column, Shodex A80M, -803, -802; eluent, THF). Melting points were measured with a MP-21 (Yamato) and uncorrected. IR spectra were obtained by the $\mathrm{KBr}$-method using a Hitachi 295 spectrophotometer. ${ }^{1} \mathrm{H}$ NMR spectra

* Present address: Applications Development Center, Engineering Plastics Ltd., 1015, Aza-Sumiyakizawa, Hodozawa, Gotemba 412, Japan. 
were recorded on a JNM-C-60HL $(60 \mathrm{MHz})$ spectrometer (JEOL) using $\mathrm{Me}_{4} \mathrm{Si}$ as an internal reference. Mass spectra were measured with a D-3000 (JEOL) and a M-80 (Hitachi) apparatus using a chemical ionization method $\left[20 \mathrm{eV}\left(3.2 \times 10^{-18} \mathrm{~J}\right)\right]$. Satisfactory patterns were obtained for all isotope peaks resulting from bromine and chlorine atoms in the mass spectra. The spectra corresponding only to ${ }^{79} \mathrm{Br}$ and ${ }^{35} \mathrm{Cl}$ have been treated in this paper.

\section{Telomerization Procedure}

Telomerization was carried out at 50,70 , and $90^{\circ} \mathrm{C}$, for 24,8 , and $4 \mathrm{~h}$ respectively under the conditions of $[\mathrm{BTCM}] /[\mathrm{MMA}]=8,[\mathrm{AIBN}]^{0.5} /[\mathrm{MMA}]=$ 0.5 (AIBN is the abbreviation for azobisisobutyronitrile). Appropriate amounts of MMA and BTCM were placed in a three-necked round bottom flask equipped with a vacuum stirrer. The mixture was heated at a prescribed temperature with stirring under a nitrogen atmosphere. AIBN was then added to the solution to initiate the reaction. After the reaction was over, the mixture was cooled to below $20^{\circ} \mathrm{C}$, and the unreacted MMA and BTCM were evaporated in vacuo. The residual viscous liquid afforded a low-polymeric product. MMA was purified by the conventional method. BTCM was distilled under reduced pressure before use, and AIBN was recrystallized from methanol.

\section{Separation and Identification of Telomers}

The $n$-mers $(n=1-3)$ were separated by silica-gel column chromatography with benzene. The development was achieved rapidly by pressing with nitrogen to avoid any side reactions in the column.

The first eluate contained 1-mer, methyl 2bromo-4,4,4-trichloro-2-methylbutyrate (1). It was purified by distillation under reduced pressure; bp $111-113^{\circ} \mathrm{C}$ [8 mmHg $\left.(1.07 \mathrm{kPa})\right]$; IR $1750 \mathrm{~cm}^{-1}$ $(\mathrm{C}=\mathrm{O})$; mass spectrum $\mathrm{m} / \mathrm{z}$ (relative intensity) 297 $\left(\mathrm{QM}^{+}, 34\right), 261$ (34), and 181 (100).

The second eluate was evaporated and the residue was recrystallized from hexane to afford syndiotactic (st)-dimer, dimethyl st-2-bromo-2,4-dimethyl-4(2,2,2-trichloroethyl)glutarate (2a); $\mathrm{mp} 58-59.5^{\circ} \mathrm{C}$; IR $1735 \mathrm{~cm}^{-1}(\mathrm{C}=\mathrm{O})$; mass spectrum $m / z$ (relative intensity) $397\left(\mathrm{QM}^{+}, 16\right), 365$ (77), 317 (48), and $101(100)$.

The third eluate, eluted immediately after the second one, was isotactic (it)-dimer, dimethyl it-2bromo-2,4-dimethyl-4-(2,2,2-trichloroethyl)gluta- rate (2b); mp $79-80^{\circ} \mathrm{C}$; IR $1730 \mathrm{~cm}^{-1}(\mathrm{C}=\mathrm{O})$; mass spectrum $\mathrm{m} / \mathrm{z}$ (relative intensity) 397 $\left(\mathrm{QM}^{+}, 15\right), 365$ (58), 317 (26), and 101 (100).

The fourth eluate afforded st-trimer, dimethyl $s t$-2-bromo-4-methoxycarbonyl-2,4,6-trimethyl-6(2,2,2-trichloroethyl)heptanedioate (3a) by a procedure similar to the above; $\mathrm{mp} 111-112^{\circ} \mathrm{C}$; IR $1745,1725 \mathrm{~cm}^{-1}(\mathrm{C}=\mathrm{O})$; mass spectrum $m / z$ (relative intensity) $497\left(\mathrm{QM}^{+}, 54\right), 465$ (100), 461 (36), 437 (23), and 417 (82).

The production ratio in the unisolated part was determined from ${ }^{1} \mathrm{H}$ NMR spectrum data.

\section{Induced Reactions of Telomers \\ Elimination Reaction of 1-mer (1) with Tri-} ethylamine (TEA). A mixture of $1(6 \mathrm{~g})$ and TEA $(30 \mathrm{ml})$ was refluxed for $13 \mathrm{~h}$. After cooling, the precipitated salt was removed, and the unreacted TEA was evaporated off. The residue was chromatographed in 2:1-benzene: cyclohexane on a silicagel column and purified by distillation in vacuo to obtain $3.6 \mathrm{~g}(83 \%)$ of methyl $\beta$-(trichloromethyl)methacrylate (4); bp $65-67^{\circ} \mathrm{C}[1 \mathrm{mmHg}(0.13$ $\mathrm{kPa})$ ]; IR $1735(\mathrm{C}=\mathrm{O})$ and $1640 \mathrm{~cm}^{-1}(\mathrm{C}=\mathrm{C})$; ${ }^{1} \mathrm{H}$ NMR $\left(\mathrm{CCl}_{4}\right) \delta 7.26$ (quartet, $1 \mathrm{H}, J=1.5 \mathrm{~Hz}$, $\mathrm{CH}), 3.77\left(\mathrm{~s}, 3 \mathrm{H}, \mathrm{CO}_{2} \mathrm{CH}_{3}\right)$, and $2.21 \mathrm{ppm}(\mathrm{d}, 3 \mathrm{H}$, $\mathrm{CH}_{3}$ ); mass spectrum $\mathrm{m} / \mathrm{z}$ (relative intensity) 217 $\left(\mathrm{QM}^{+}, 40\right), 181(100)$, and 153 (28).

Reaction between st-Dimer (2a) and TEA. A mixture of $2 \mathrm{a}(3 \mathrm{~g})$ and TEA $(60 \mathrm{ml})$ was refluxed for $60 \mathrm{~h}$. The reaction mixture was treated in a manner similar to that used for $\mathbf{1}$, and the following products were isolated by silica-gel column chromatography with benzene: $1.05 \mathrm{~g}(44 \%)$ of dimethyl 2-methyl-4-methylene-2-(2,2,2-trichloroethyl)glutarate (5a), a colorless viscous liquid; IR $1720(\mathrm{C}=\mathrm{O})$ and $1640 \mathrm{~cm}^{-1}(\mathrm{C}=\mathrm{C}) ;{ }^{1} \mathrm{H}$ NMR $\left(\mathrm{CCl}_{4}\right) \delta 6.19\left(\mathrm{~d}, 1 \mathrm{H}, J=1.5 \mathrm{~Hz},=\mathrm{CH}_{2}\right), 5.51(\mathrm{~s}$, $\left.1 \mathrm{H},=\mathrm{C}_{2}\right), 3.72\left(\mathrm{~s}, 3 \mathrm{H}, \mathrm{CO}_{2} \mathrm{CH}_{3}\right), 3.64(\mathrm{~s}, 3 \mathrm{H}$, $\left.\mathrm{CO}_{2} \mathrm{C}_{3}\right), 3.64\left(\mathrm{~d}, 1 \mathrm{H}, J=15 \mathrm{~Hz}, \mathrm{CH}_{2}\right), 2.80(\mathrm{~d}, 1 \mathrm{H}$, $\left.\mathrm{CH}_{2}\right), 2.59\left(\mathrm{~s}, 2 \mathrm{H}, \mathrm{C}_{2}\right)$, and $1.38 \mathrm{ppm}(\mathrm{s}, 3 \mathrm{H}$, $\mathrm{CH}_{3}$ ); mass spectrum $\mathrm{m} / \mathrm{z}$ (relative intensity) 317 $\left(\mathrm{QM}^{+}, 46\right), 285$ (100), and $247(43)$, and $0.5 \mathrm{~g} \mathrm{(22 \% )}$ of trans-4-methoxycarbonyl-2,4-dimethyl-2(2,2,2-trichloroethyl)-4-butanolide (6b); $\mathrm{mp} \mathrm{94-}$ $95.5^{\circ} \mathrm{C}$ (recrystallized from hexane); IR 1765,1735 $\mathrm{cm}^{-1}(\mathrm{C}=\mathrm{O})$; mass spectrum $\mathrm{m} / \mathrm{z}$ (relative intensity) $303\left(\mathrm{QM}^{+}, 100\right), 267$ (70), 243 (40), 231 (5), and 207 (18).

Reaction of it-Dimer (2b) and TEA. A mixture of 
$2 \mathbf{b}(1.2 \mathrm{~g})$ and TEA $(24 \mathrm{ml})$ was treated in a manner similar to that used for 2a to yield the following products: $0.12 \mathrm{~g} \mathrm{(13 \% )}$ of 5a, $0.24 \mathrm{~g}(26 \%)$ of $6 \mathbf{b}$, and $0.23 \mathrm{~g}(24 \%)$ of dimethyl 2,4-dimethyl-4-(2,2,2trichloroethyl)-2-pentenedioate (5b), a colorless viscous liquid; IR $1725(\mathrm{C}=\mathrm{O})$ and $1625 \mathrm{~cm}^{-1}$ $(\mathrm{C}=\mathrm{C}) ;{ }^{1} \mathrm{H}$ NMR $\left(\mathrm{CCl}_{4}\right) \delta 6.71$ (quartet, $1 \mathrm{H}, J=$ $1.5 \mathrm{~Hz}, \mathrm{C} \underline{\mathrm{H}}), 3.71\left(\mathrm{~s}, 6 \mathrm{H}, \mathrm{CO}_{2} \mathrm{C}_{3}\right), 3.64(\mathrm{~d}, 1 \mathrm{H}, J=$ $\left.15 \mathrm{~Hz}, \mathrm{C}_{2}\right), 3.17\left(\mathrm{~d}, 1 \mathrm{H}, \mathrm{C}_{2}\right), 1.75\left(\mathrm{~d}, 3 \mathrm{H}, \mathrm{C}_{3}\right)$, and $1.64 \mathrm{ppm}\left(\mathrm{s}, 3 \mathrm{H}, \mathrm{CH}_{3}\right)$; mass spectrum $\mathrm{m} / z$ (relative intensity) $317\left(\mathrm{QM}^{+}, 100\right), 285$ (91), and 247 (43).

Pyrolysis of Dimers. The two dimers were separately heated at $200^{\circ} \mathrm{C}$ for $2 \mathrm{~h}$. Lactone $6 \mathbf{b}$ was quantitatively obtained from $\mathbf{2 b}$. Similarly, $\mathbf{2 a}$ produced cis-4-methoxycarbonyl-2,4-dimethyl-2(2,2,2-trichloroethyl)-4-butanolide (6a); mp 73.5$75^{\circ} \mathrm{C}$ (recrystallized from hexane); IR 1770, 1740 $\mathrm{cm}^{-1}(\mathrm{C}=\mathrm{O})$; mass spectrum $\mathrm{m} / \mathrm{z}$ (relative intensity) $303\left(\mathrm{QM}^{+}, 100\right), 267$ (48), 243 (37), 231 (42), and 207 (5).

Cyclization of Dimers by Silica Gel. To a benzene solution of a dimer $(0.5 \mathrm{~g}$ in $15 \mathrm{ml}), 5 \mathrm{~g}$ of silica gel was added, and the suspension was stirred for $72 \mathrm{~h}$ at room temperature. The conversions were calculated to be $11 \%(\mathbf{2 a} \rightarrow \mathbf{6 a})$ and $100 \%(\mathbf{2 b} \rightarrow \mathbf{6 b})$, respectively, from the ${ }^{1} \mathrm{H}$ NMR data.

Reaction of Trimers with Silica Gel. Silica gel was added to a benzene solution of a trimer, and the suspension was heated at $50^{\circ} \mathrm{C}$ for $24 \mathrm{~h}$. Compound 3a afforded cis-4-methoxycarbonyl-2-(2-methoxycarbonyl-2-methyl-4,4,4-trichlorobutyl)-2,4-dimethyl-4-butanolide (7a) in a $75 \%$ yield; $\mathrm{mp} 65.5-$ $67^{\circ} \mathrm{C}$ (recrystallized from 3:1-cyclohexane: ethyl acetate); IR 1780,1755 , and $1740 \mathrm{~cm}^{-1}(\mathrm{C}=\mathrm{O}) ;{ }^{1} \mathrm{H}$ NMR (benzene- $\left.d_{6}\right) \delta 3.53\left(\mathrm{~d}, 1 \mathrm{H}, J=15.6 \mathrm{~Hz}, \mathrm{CH}_{2}\right)$, 3.28 (s, $3 \mathrm{H}, \mathrm{CO}_{2} \mathrm{CH}_{3}$ ), 3.24 (s, $3 \mathrm{H}, \mathrm{CO}_{2} \mathrm{CH}_{3}$ ), 2.48 (d, $\left.1 \mathrm{H}, \mathrm{CH}_{2}\right), 2.38\left(\mathrm{~d}, 1 \mathrm{H}, J=13.5 \mathrm{~Hz}, \mathrm{CH}_{2}\right), 2.00$ (d, $\left.1 \mathrm{H}, \mathrm{C}_{2}\right), 1.65$ (s, 2H, $\left.\mathrm{C}_{2}\right), 1.45\left(\mathrm{~s}, 3 \mathrm{H}, \mathrm{CH}_{3}\right)$, $1.38\left(\mathrm{~s}, 3 \mathrm{H}, \mathrm{CH}_{3}\right)$, and $1.09 \mathrm{ppm}\left(\mathrm{s}, 3 \mathrm{H}, \mathrm{CH}_{3}\right)$; mass spectrum $m / z$ (relative intensity) $403\left(\mathrm{QM}^{+}, 100\right)$, 371 (63), and 367 (12). Trimers containing heterotactic (ht)-trimer (3b) produced primarily trans-4methoxycarbonyl-2-(2-methoxycarbonyl-2-methyl4,4,4-trichlorobutyl)-2,4-dimethyl-4-butanolide (7b) in a reasonable yield; $\mathrm{mp} 174-175^{\circ} \mathrm{C}$ (recrystallized from methanol); IR 1780, 1755, and 1740 $\mathrm{cm}^{-1}(\mathrm{C}=\mathrm{O}) ;{ }^{1} \mathrm{H}$ NMR (benzene- $\left.d_{6}\right) \cdot \delta 3.31$ (d, $\left.1 \mathrm{H}, J=13.2 \mathrm{~Hz}, \mathrm{CH}_{2}\right), 3.21\left(\mathrm{~s}, 6 \mathrm{H}, \mathrm{CO}_{2} \mathrm{C}_{3}\right)$, 2.41 (d, 2H, $\left.J=14.4 \mathrm{~Hz}, \underline{\mathrm{CH}}_{2}\right), 2.17\left(\mathrm{~d}, 1 \mathrm{H}, \mathrm{C}_{2}\right)$,

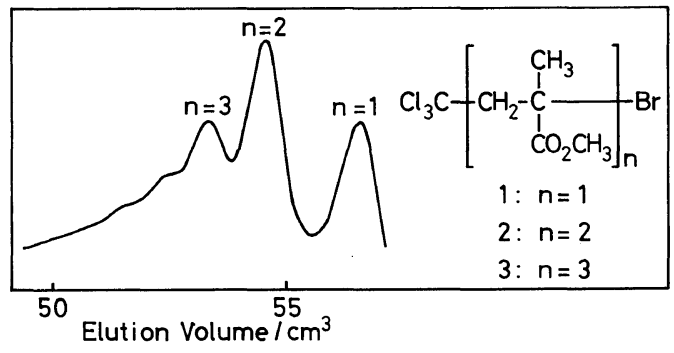

Figure 1. GPC chromatogram of the product obtained at $90^{\circ} \mathrm{C}$.

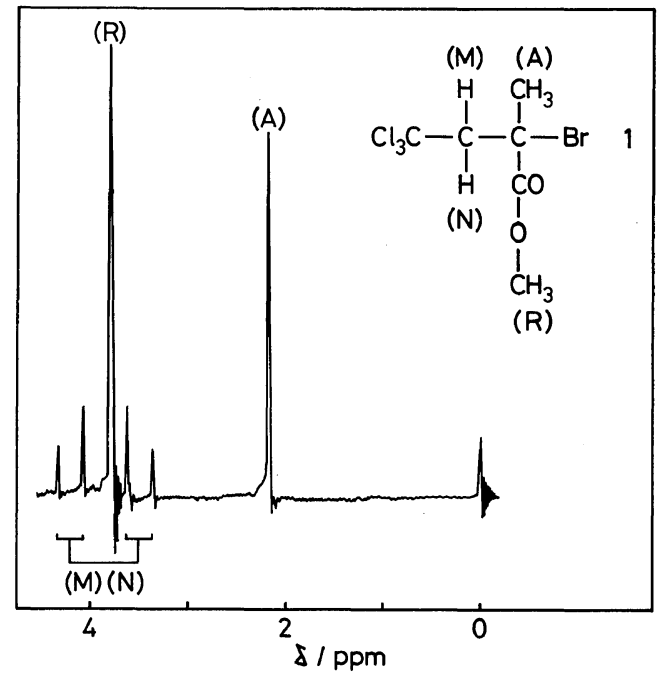

Figure 2. ${ }^{1} \mathrm{H}$ NMR spectrum of 1 -mer (1) in $\mathrm{CCl}_{4}$.

$1.86\left(\mathrm{~d}, 1 \mathrm{H}, \mathrm{C}_{2}\right), 1.40\left(\mathrm{~s}, 6 \mathrm{H}, \mathrm{C}_{3}\right), 1.36(\mathrm{~d}, 1 \mathrm{H}$, $\left.\mathrm{C}_{2}\right)$, and $1.01\left(\mathrm{~s}, 3 \mathrm{H}, \mathrm{CH}_{3}\right) \mathrm{ppm}$; mass spectrum $\mathrm{m} / z$ (relative intensity) $403\left(\mathrm{QM}^{+}, 100\right), 371(66)$, and 367 (34).

\section{RESULTS AND DISCUSSION}

Figure 1 shows a typical GPC chromatogram of the product obtained through the present telomerization. The yield of $n$-mers $(n=1-3)$ was about $70 \%$ of the overall one, and an increase in the reaction temperature tended to decrease the molecular weight.

\section{${ }^{1} H$ NMR Structural Analysis of Telomers}

1 -mer (1). The ${ }^{1} \mathrm{H}$ NMR spectrum of $\mathbf{1}$ is shown in Figure 2. The singlets at 2.19 and $3.81 \mathrm{ppm}$ correspond to the methyl protons (A) and those of 
the ester group (R), respectively. Since the two geminal methylene protons $(\mathrm{M})$ and $(\mathrm{N})$ are expected to exhibit a typical $\mathrm{AB}$ pattern due to the magnetic nonequivalence, the quartet broadened at $3.85 \mathrm{ppm}$ may be assigned to the (M)- and (N)protons.

Dimers (2). Since 2 has two asymmetric carbon atoms, there are two possible diastereoisomers, $\mathbf{2 a}$ and $\mathbf{2 b}$.

${ }^{1} \mathrm{H}$ NMR spectroscopy is an effective method for
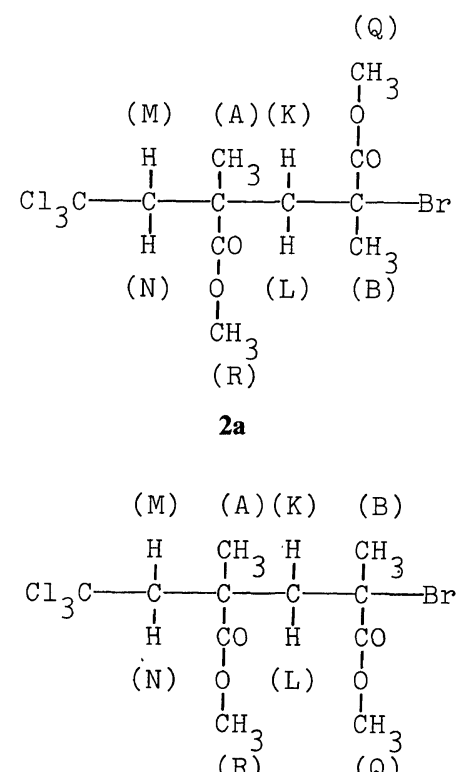

(R) (Q)

2b

Table I. ${ }^{1} \mathrm{H}$ NMR parameters of 1 -mer (1), st- (2a), and it- (2b) dimers

\begin{tabular}{|c|c|c|c|c|c|c|}
\hline \multirow{2}{*}{ Proton } & \multirow{2}{*}{ Symbol } & \multicolumn{5}{|c|}{ Chemical shift $\delta / \mathrm{ppm}$} \\
\hline & & 1 & \multicolumn{2}{|c|}{$2 \mathbf{a}$} & \multicolumn{2}{|c|}{$\mathbf{2 b}$} \\
\hline$-\mathrm{CH}_{3}$ & A & 2.19 & \multicolumn{2}{|c|}{1.83} & \multicolumn{2}{|c|}{1.97} \\
\hline$-\mathrm{CH}_{3}$ & B & & \multicolumn{2}{|c|}{1.29} & \multicolumn{2}{|c|}{1.55} \\
\hline \multirow{3}{*}{$-\mathrm{CH}_{2-}^{-}$} & $\mathrm{K}, \mathrm{L}$ & & 3.02 & 2.78 & 2.97 & 2.72 \\
\hline & & & 2.75 & 2.51 & 2.49 & 2.24 \\
\hline & & & {$[16.2]$} & (14.4) & {$[28.8]$} & $(15.0)$ \\
\hline \multirow[t]{3}{*}{$-\mathrm{CH}_{2}-$} & $\mathrm{M}, \mathrm{N}$ & $4.34 \quad 4.08$ & 3.64 & 3.40 & 3.71 & 3.46 \\
\hline & & $3.63 \quad 3.37$ & 2.96 & 2.72 & 2.99 & 2.74 \\
\hline & & {$[42.6]^{\mathrm{a}} \quad(15.6)^{\mathrm{b}}$} & {$[40.8]$} & (14.4) & [43.2] & $(15.0)$ \\
\hline$-\mathrm{CO}_{2} \mathrm{CH}_{3}$ & $\mathrm{Q}$ & \multirow[b]{2}{*}{3.81} & \multicolumn{2}{|c|}{3.68} & \multicolumn{2}{|c|}{3.66} \\
\hline$-\mathrm{CO}_{2} \mathrm{CH}_{3}$ & $\mathrm{R}$ & & \multicolumn{2}{|c|}{3.77} & \multicolumn{2}{|c|}{3.76} \\
\hline
\end{tabular}

a [ ]: Difference in chemical shifts $\Delta \delta$ in $\mathrm{Hz}$.

b ( ): Coupling const $J$ in $\mathrm{Hz}$. dimer (2a); ii) it-dimer (2b).

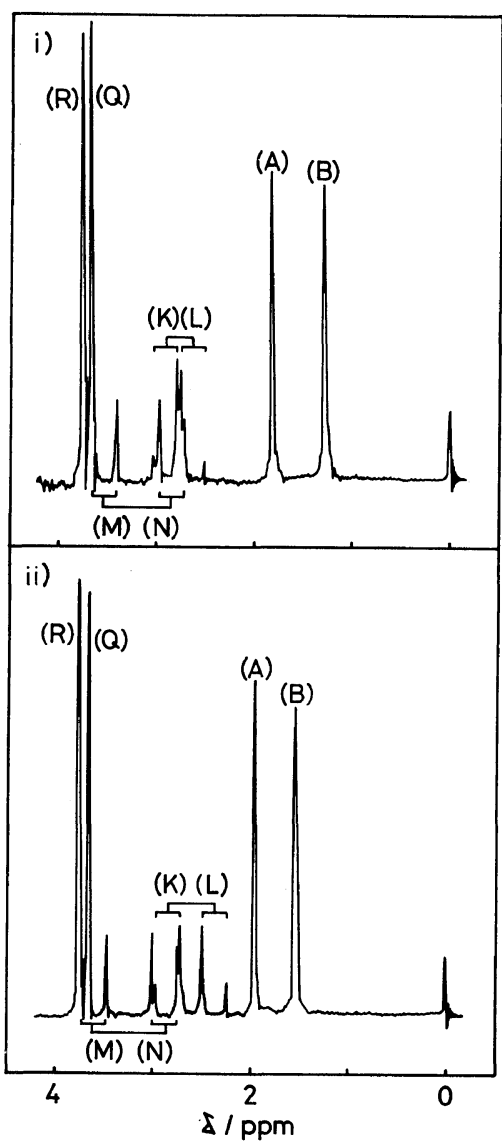

Figure 3. ${ }^{1} \mathrm{H}$ NMR spectra of dimers (2) in $\mathrm{CCl}_{4}$ : i) st- 
determining the tacticities of telomers. The magnetic environment about the two geminal methylene protons $(\mathrm{K})$ and $(\mathrm{L})$ is obviously different for $\mathbf{2 a}$ and $\mathbf{2 b}$. Therefore, the corresponding signals should show characteristic differences with each other. That is, 2a will indicate signals resembling a singlet owing to the nearly equivalent protons, whereas $\mathbf{2 b}$ will exhibit an $\mathrm{AB}$ pattern similar to that of other methylene protons $(\mathrm{M})$ and $(\mathrm{N})$ owing to nonequivalent protons.

Figure 3 shows the ${ }^{1} \mathrm{H}$ NMR spectra of two diastereoisomers of isolated dimers. On the basis of the assignment of the proton signals summarized in Table I, spectra i) and ii) in Figure 3 were found to correspond to $\mathbf{2 a}$ and $\mathbf{2 b}$, respectively.

The methyl protons (A) and (B) of 2a resonated in higher magnetic fields relative to those of $\mathbf{2 b}$. This tendency may be explained by a shielding effect of

Table II. Temperature dependence of the production ratio of $s t$ - (2a) and it- (2b) dimers

\begin{tabular}{ccccc}
\hline & & \multicolumn{3}{c}{ Temp $/{ }^{\circ} \mathbf{C}$} \\
\cline { 3 - 5 } & Dimer & 50 & 70 & 90 \\
\hline Production & $\mathbf{2 a}$ & 85 & 78 & 75 \\
ratio $/ \%$ & $\mathbf{2 b}$ & 15 & 22 & 25
\end{tabular}

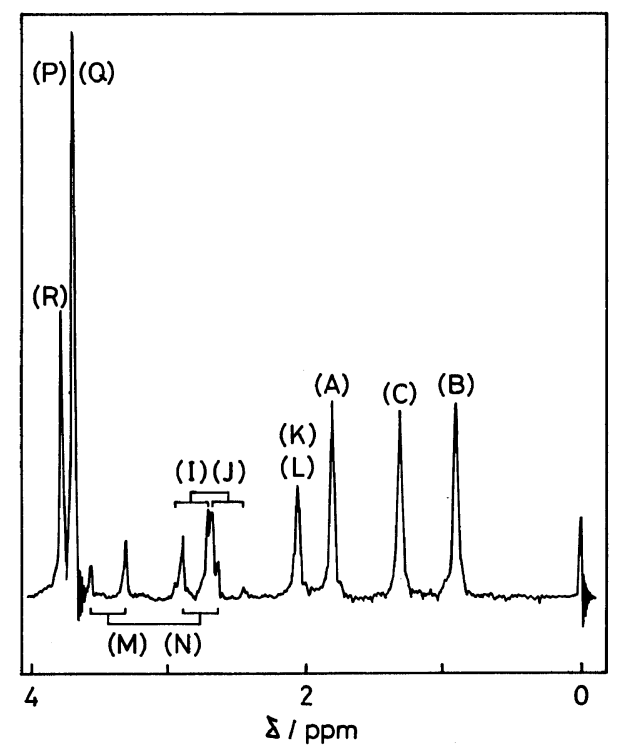

Figure 4. ${ }^{1} \mathrm{H}$ NMR spectrum of $s t$-trimer (3a) in $\mathrm{CCl}_{4}$. the ester groups toward the methyl protons of $\mathbf{2 a}$. Although an electronegative effect of the trichloromethyl groups on the methyl protons (A) and (R) is weakened by the methylene groups between them, this effect will be even larger than a similar effect of the bromine atoms on the methyl protons (B) and (Q). Consequently, the signals of the methyl protons (A) and (R) must shift to magnetic fields lower than those of the methyl protons (B) and (Q), respectively.

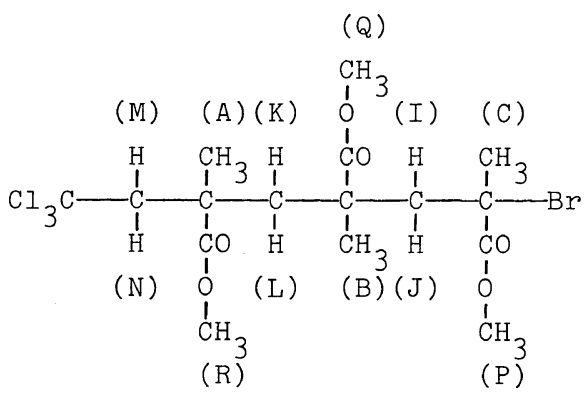

$3 \mathbf{a}$

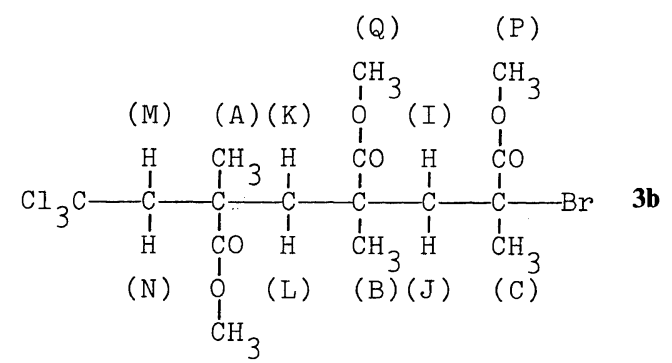

(R)<smiles>COC(=O)C(C)(C(=O)OC)C(C)(C)C(C)C(C)(Br)C(C)(Br)C(C)(Br)Br</smiles><smiles>[R17]OC(=O)C(C)(C(C)C)C(C)C(C)(OC)C(C)C(C)(Br)C(C)OC</smiles>

3d 
Table III. ${ }^{1} \mathrm{H}$ NMR parameters of $s t$-trimer (3a)

\begin{tabular}{lcc}
\hline \multicolumn{1}{c}{ Proton } & Symbol & Chemical shift $\delta /$ ppm \\
\hline$-\mathrm{CH}_{3}$ & $\mathrm{~A}$ & 1.77 \\
$-\mathrm{CH}_{3}$ & B & 0.87 \\
$-\mathrm{CH}_{3}$ & $\mathrm{C}$ & 1.28 \\
$-\mathrm{CH}_{2}-$ & $\mathrm{I}, \mathrm{J}$ & 2.902 .672 .642 .41 \\
& & {$[15.6]^{\mathrm{a}}(13.8)^{\mathrm{b}}$} \\
$-\mathrm{CH}_{2}-$ & $\mathrm{K}, \mathrm{L}$ & 2.02 \\
$-\mathrm{CH}_{2}-$ & $\mathrm{M}, \mathrm{N}$ & 3.533 .282 .852 .60 \\
& & {$[40.8](15.0)$} \\
$-\mathrm{CO}_{2} \mathrm{CH}_{3}$ & P & 3.67 \\
$-\mathrm{CO}_{2} \mathrm{CH}_{3}$ & $\mathrm{Q}$ & 3.67 \\
$-\mathrm{CO}_{2} \mathrm{CH}_{3}$ & $\mathrm{R}$ & 3.75 \\
\hline
\end{tabular}

a [ ]: Difference in chemical shifts $\Delta \delta$ in $\mathrm{Hz}$.

b ( ): Coupling const $J$ in $\mathrm{Hz}$.

The formation of $\mathbf{2 a}$ was favored over that of $\mathbf{2 b}$ as shown in Table II, but the production ratio of $\mathbf{2 b}$ increased with the reaction temperature. It is considered that the temperature dependence of $\mathbf{2 b}$ is larger than that of $\mathbf{2 a}$ due to steric hindrance.

Trimers (3). Since 3 has three asymmetric carbon atoms, four possible diastereoisomers can be formed, 3a, 3b, $h t$ - (3c), and it- (3d) trimers.

However, the diastereoisomer isolated was $\mathbf{3 a}$ only. Figure 4 shows the ${ }^{1} \mathrm{H}$ NMR spectrum of 3a, and the assignment of the proton signals is given in Table III.

Among the three methyl protons (A), (B), and (C) of $3 \mathbf{a}$, the $(\mathrm{A})$ protons are located in a magnetic environment similar to the methyl protons (A) of 2a. The singlet at $1.77 \mathrm{ppm}$ was therefore assigned to the (A) protons. Furthermore, since the (C) protons correspond to the methyl protons (B) of $\mathbf{2 a}$, the singlet at $1.28 \mathrm{ppm}$ is assignable to the (C) protons and the central methyl protons (B) resonate at $0.87 \mathrm{ppm}$ as a singlet. The assignment of the two methylene protons on both sides may be estimated also on the basis of the corresponding methylene protons of $2 \mathrm{a}$. The ambiguous $\mathrm{AB}$ pattern consisting of signals at 2.90, 2.67, 2.64 and $2.41 \mathrm{ppm}$ is due to the (I) and (J) protons, and the typical AB pattern consisted of signals at 3.53, 3.28, 2.85 and $2.60 \mathrm{ppm}$ is due to the $(\mathrm{M})$ and $(\mathrm{N})$ protons. The central methylene protons $(\mathrm{K})$ and $(\mathrm{L})$ resonate at $2.02 \mathrm{ppm}$ as a singlet, indicating that they are not influenced by the end groups.

The ${ }^{1} \mathrm{H}$ NMR spectrum of the whole unisolated 3

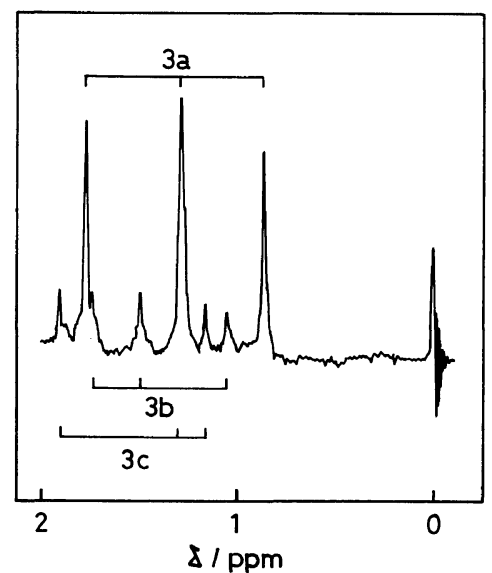

Figure 5. ${ }^{1} \mathrm{H}$ NMR spectrum of methyl proton resonance region of trimers (3) obtained at $70^{\circ} \mathrm{C}\left(\mathrm{CCl}_{4}\right)$.

Table IV. Chemical shifts $\delta$ in ppm of methyl protons of the resulting trimers

\begin{tabular}{|c|c|c|c|}
\hline \multirow{2}{*}{ Symbol } & \multicolumn{3}{|c|}{$\delta$} \\
\hline & $\mathbf{3 a}$ & $\mathbf{3 b}$ & $3 c$ \\
\hline A & $1.77(1.83)^{\mathrm{a}}$ & $1.74(1.83)$ & $1.90(1.97)$ \\
\hline B & 0.87 & 1.04 & 1.15 \\
\hline $\mathrm{C}$ & $1.28(1.29)$ & $1.49(1.55)$ & $1.30(1.29)$ \\
\hline
\end{tabular}

${ }^{a}$ ( ): Chemical shifts estimated from the (A)- and (B)proton signals of the dimers (see Table I).

in the methyl proton region is shown in Figure 5.

The formation of two diastereoisomers is predictable besides that of $\mathbf{3 a}$, since some smaller signals are present in addition to the signals corresponding to 3a in Figure 5. The magnetic environment about the (A)- and (C)-protons of 3 resembles that about the (A)- and (B)-protons of 2, respectively. Therefore, all the signals can be assigned as shown in Table IV. The production ratio of the resulting three trimers was $3 \mathbf{a}: \mathbf{3 b}: \mathbf{3 c}=58: 21: 21$ as determined by the area ratio of the corresponding signals in Figure 5. However, the presence of $\mathbf{3 d}$ was not confirmed, and the formation of $\mathbf{3 d}$ seems difficult in this system.

\section{Induced Reactions of Telomers}

1-mer (1). The reaction of 1 with TEA gave 4 in good yield, and the elimination of hydrogen chloride was not observed in this reaction. These results demonstrate that the trichloromethyl radical 
Separation and Structure of MMA : BTCM Telomers<smiles>CC=C(C)C(=O)OC</smiles>

4<smiles>C=C(CC)CC(C)(CC)C(=O)OC</smiles>

$5 \mathbf{a}$

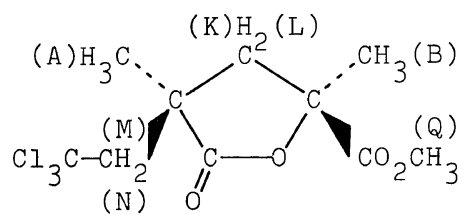

$6 a$

resulting from BTCM is selectively attached to the $\beta$-position of the double bond of MMA and that the bromine atom on $\mathbf{1}$ is eliminated much more easily than the chlorine atom on $\mathbf{1}$.

Dimers (2). The reaction between 2 and TEA was carried out in a manner similar to that with $\mathbf{1}$, and $\mathbf{5 a}$ and $\mathbf{6 b}$ were obtained from $\mathbf{2 a}$, whereas $\mathbf{2 b}$ gave $\mathbf{5 a}, \mathbf{6 b}$ and $\mathbf{5 b}$. Since this reaction with TEA proceeds through a trans elimination mechanism, the conformation between the leaving hydrogen and

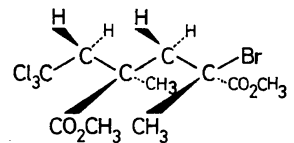

2A

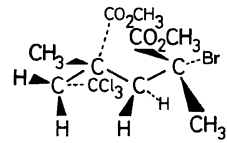

2B<smiles>CCOC(C)=CC(C)(CC)C(=O)OC</smiles>

5b

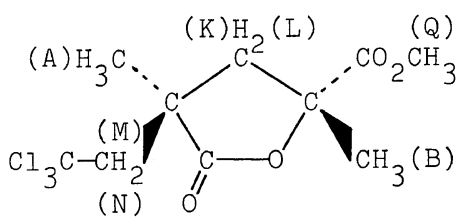

6b bromine atoms must be a trans form to produce $\mathbf{5 b}$ according to Saytzeff's law. Olefin $\mathbf{5 b}$ was produced in preference to $\mathbf{5 a}$ in the reaction of $\mathbf{2 b}$, but $\mathbf{5 b}$ was not obtained at all in the reaction of $2 \mathbf{a}$. That the $i t$ poly(methyl methacrylate) (PMMA) has a $5_{1}$ helical conformation, and that the st-PMMA has the $1: 1$ mixture of $T . T$ and $T$-cis coformations have already been reported by Amiya, et al. ${ }^{16}$ If similar conformations are applied to $\mathbf{2} \mathbf{a}$ and $\mathbf{2} \mathbf{b}$, the difference in reactivity may be satisfactorily explained. That is, the most stable conformations of $\mathbf{2 a}$ and $\mathbf{2 b}$ are $\mathbf{2 A}$ and $\mathbf{2 B}$, respectively.

Lactone $\mathbf{6} \mathbf{b}$ is a ring compound formed through the elimination of the methyl radical at the $\gamma$-ester group and the bromine atom of dimers. If the production of $\mathbf{6 b}$ occurs by trans elimination as in the case of the olefins $\mathbf{5 a}$ and $\mathbf{5 b}$, different lactones

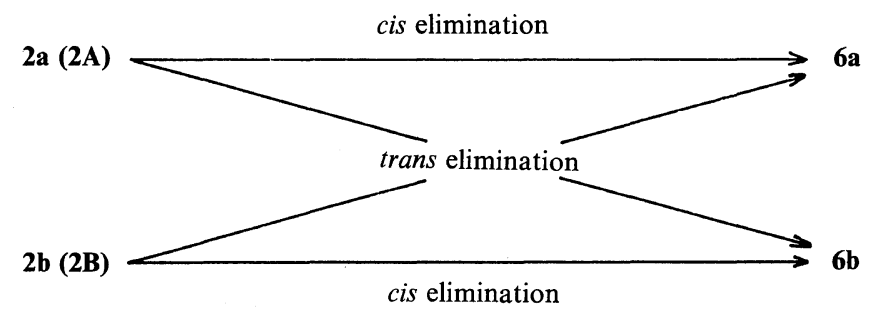

Scheme I. 


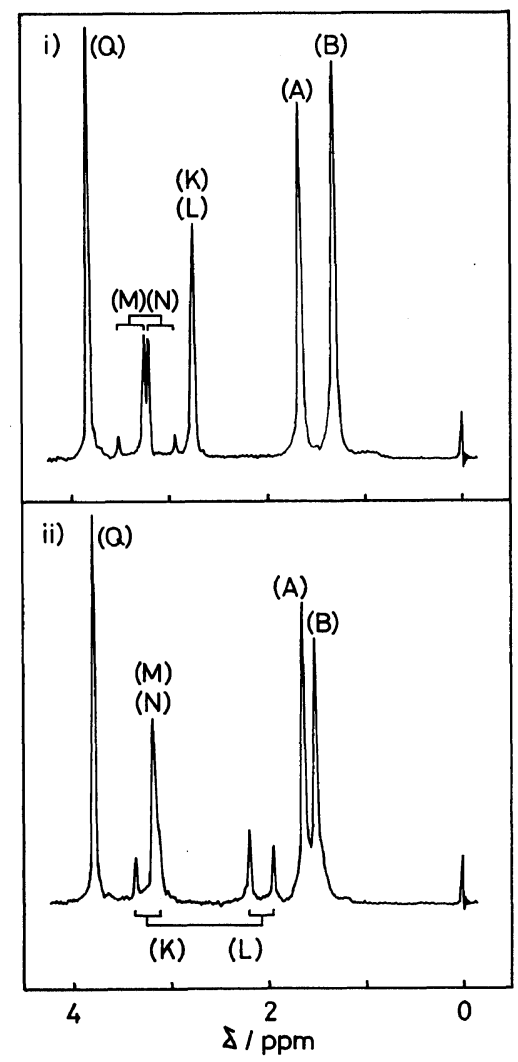

Figure 6. ${ }^{1} \mathrm{H}$ NMR spectra of dimer-lactones in $\mathrm{CCl}_{4}$ : i) cis-type (6a); ii) trans-type (6b).

will be generated by the following pathway: $\mathbf{2 a} \rightarrow \mathbf{6} \mathbf{b}$ and $\mathbf{2 b \rightarrow 6 a}$. But both starting materials gave lactone $\mathbf{6 b}$. This may be explained by the difference in the conformations of $\mathbf{2 a}$ and $\mathbf{2 b}$. In the conformational 2A, the trans elimination tends to occur since the ethereal oxygen at the $\gamma$-ester group is situated on the opposite side of the bromine atom. In contrast, the cis elimination is dominant in the conformational 2B since the oxygen is situated on the same side of the bromine atom (Scheme I).

Furthermore, heating of 2 without any solvent resulted in the cis elimination quantitatively, and $\mathbf{2 a}$ and $2 \mathbf{b}$ afforded $6 \mathbf{a}$ and $6 \mathbf{b}$, respectively.

Similar reactions were also observed by the catalytic action of silica gel. However, the reactivities of $\mathbf{2 a}$ and $\mathbf{2 b}$ were greatly different in this case and the conversion of $\mathbf{2 b}$ was larger than that of $\mathbf{2 a}$. The validity of the two estimated dimer conformations may be supported by the difference in reactivity.

The ${ }^{1} \mathrm{H}$ NMR spectra of the dimer-lactones, $6 \mathrm{a}$
Table V. ${ }^{1} \mathrm{H}$ NMR parameters of cis- (6a) and trans- $(\mathbf{6 b})$ lactones

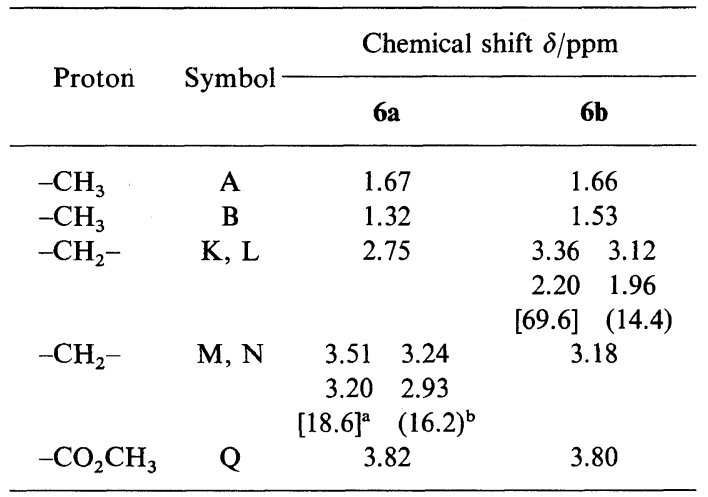

${ }^{\text {a }}$ [ ]: Difference in chemical shifts $\Delta \delta$ in $\mathrm{Hz}$.

b ( ): Coupling const $J$ in $\mathrm{Hz}$.<smiles>[CH]CC(C)(CC)C[C@]1(C)C[C@@](C)(C(=O)OC)OC1=O</smiles>

$7 \mathbf{a}$<smiles></smiles>

7b

and $\mathbf{6 b}$, are shown in Figure 6, and the assignment of the proton signals is summarized in Table V.

Since the free rotation of the trichloroethyl groups becomes possible by the ring formation, the signals of the methylene protons $(\mathrm{M})$ and $(\mathrm{N})$ may be equivalent. Actually, the corresponding signal of $\mathbf{6 b}$ assumed a singlet. However, that of $\mathbf{6 a}$ assumed an ambiguous $A B$ pattern, since the new rotational hindrance of the methyl proton (A) against the trichloroethyl group is brought about by the repulsive force between the trichloroethyl and the ester groups. On the other hand, the methylene protons $(\mathrm{K})$ and $(\mathrm{L})$ will show a distinct $\mathrm{AB}$ pattern due to the magnetic nonequivalence, since they are situated apart from each other on either side of the 
five-membered ring. The predicted pattern of the methylene protons was observed for $\mathbf{6 b}$, but $\mathbf{6 a}$ showed a singlet. In the case of $\mathbf{6 a}$, there is a repulsive force between the trichloroethyl and the ester groups.

It is therefore anticipated that isolation of the methylene protons $(\mathrm{K})$ and $(\mathrm{L})$ is promoted and that they are equivalent.

Trimers (3). As in the case of 2 , trimers 3 were successfully converted to the corresponding lactones by the catalytic action of silica gel. For instance, 7a was obtained by the reaction of 3a. A similar reaction was attempted with a mixture of 3 containing primarily $\mathbf{3 b}$. As a result, $\mathbf{7 b}$ was obtained as the main product and was easily isolated because of the poorer solubility of $\mathbf{7 b}$ in organic solvents than that of other components. The ${ }^{1} \mathrm{H}$ NMR spectra of $\mathbf{7 a}$ and $\mathbf{7 b}$ were consistently analyzed using the results in Tables III and V.

Acknowledgement. The authors are indebted to Dr. S. Nishi of the National Chemical Laboratory for Industry for his assistance in the mass spectra measurements.

\section{REFERENCES}

1. T. Sasaki, T. Migita, K. Izawa, and H. Tomioka,
“Fukahannō,” Maruzen Co., Tokyo, 1975, pp 235300.

2. M. S. Kharasch, O. Reinmuth, and W. H. Urry, $J$. Am. Chem. Soc., 69, 1105 (1947).

3. M. S. Kharasch, E. V. Jensen, and W. H. Urry, J. Am. Chem. Soc., 68, 154 (1946).

4. M. S. Kharasch, E. V. Jensen, and W. H. Urry, J. Am. Chem. Soc., 69, 1100 (1947).

5. M. S. Kharasch and M. Sage, J. Org. Chem., 14, 537 (1949).

6. M. S. Kharasch and H. N. Friedlander, J. Org. Chem., 14, 239 (1949).

7. C. A. Barson, R. R. Mather, and J. C. Robb, Trans. Faraday Soc., 66, 2585 (1970).

8. C. A. Barson, A. R. Luxton, and J. C. Robb, J. Chem. Soc., Faraday Trans. 1, 68, 1666 (1972).

9. C. A. Barson, R. A. Batten, and J. C. Robb, Eur. Polym. J., 10, 97 (1974).

10. C. A. Barson and R. Ensor, Eur. Polym. J., 13, 53 (1977).

11. S. Fujishige, Makromol. Chem., 176, 225 (1976).

12. S. Fujishige, Makromol. Chem., 177, 375 (1976).

13. A. Bledzki and D. Braun, Makromol. Chem., 182, 1047 (1981).

14. A. Bledzki, H. Balard, and D. Braun, Makromol. Chem., 182, 1057 (1981).

15. H. Balard, A. Bledzki, and D. Braun, Makromol. Chem., 182, 1063 (1981).

16. S. Amiya, I. Ando, S. Watanabe, and R. Chûjô, Polym. J., 6, 194 (1974). 